\title{
Commentary: Neural substrates of embodied natural beauty and social endowed beauty: An fMRI study
}

\author{
Marcos Nadal ${ }^{1,2 *}$, Víctor Gallardo ${ }^{3}$ and Gisèle Marty ${ }^{1,2}$ \\ ${ }^{1}$ Department of Psychology, University of the Balearic Islands, Palma, Spain, ${ }^{2}$ Human Evolution and Cognition Group, \\ Spanish National Research Council (CSIC), University of the Balearic Islands, Palma, Spain, ${ }^{3}$ Hospital Can Misses, Ibiza, \\ Spain
}

Keywords: neuroaesthetics, beauty, objective, subjective, sense of beauty

\section{A commentary on}

Neural substrates of embodied natural beauty and social endowed beauty: An fMRI study by Zhang, W., He, X., Lai, S., Wan, J., Lai, S., Zhao, X., et al. (2017). Sci. Rep. 7, 7125. doi: 10.1038/s41598-017-07608-8

\section{OPEN ACCESS}

Edited by:

Arthur M. Jacobs,

Freie Universität Berlin, Germany

Reviewed by:

Markus J. Hofmann, University of Wuppertal, Germany

*Correspondence: Marcos Nadal marcos.nadal@uib.es

Received: 06 November 2017 Accepted: 24 November 2017 Published: 05 December 2017

Citation:

Nadal M, Gallardo V and Marty G

(2017) Commentary: Neural substrates of embodied natural beauty and social endowed beauty: An fMRI study. Front. Hum. Neurosci. 11:596.

doi: 10.3389/fnhum.2017.00596
The use of neuroimaging techniques to study aesthetic valuation has invigorated scientific aesthetics (Chatterjee, 2011; Nadal and Pearce, 2011). These techniques have improved our understanding of the relation between psychological processes involved in aesthetic valuation and the underlying neural mechanisms, they have made it possible to study cognitive or affective processes unaccompanied by overt behavioral responses, and they have provided crucial constraints on cognitive theories and models (Pearce et al., 2016). Not only have neuroimaging techniques led to new questions about aesthetics, they have produced new evidence capable of settling old debates.

In this vein, Zhang et al. (2017) recently used fMRI to explore the dispute between objectivist and subjectivist philosophies of beauty: Is beauty a quality of objects or a quality we attribute to objects? They asked participants to judge unfamiliar ancient Chinese characters as beautiful or ugly. Half of the characters were pictographs, referring to concrete objects and outlining their shape. The other half were ideographic symbols, referring to abstract social concepts. The authors assumed that beauty judgments of pictographs were based on their objective features, and beauty judgments of ideographs on their subjective socially constructed meanings.

Zhang et al. (2017) found widespread brain activity common to judgments of both sorts of characters, but they also found activity in certain brain regions specific either to judging the beauty of pictographs or judging the beauty of ideographs. They saw in these specific patterns the neural signatures of two distinct kinds of beauty, one related to object features and another to subjective processes. Zhang et al. (2017) argued that their results constitute evidence for a sense of beauty that responds to two different kinds of attributes: objective features ("embodied natural beauty"), and subjective social constructions ("social endowed beauty").

However, motivated by their assumption that pictographs are judged for their objective features and ideographs for their subjective social meanings, Zhang et al. (2017) overlooked the most parsimonious interpretation of their results. Differences in brain activity related to the beauty judgments of pictographs and ideographs most probably owe to the former being representational and the latter being abstract. That the characters differed in abstraction is a matter of fact: they were chosen so. That they differed as to the source of their beauty is a matter of unsupported speculation: the objective features of ideographs and the meanings of pictographs can also be judged as beautiful or ugly. Zhang et al. (2017), thus, did not identify brain activity corresponding to "embodied natural beauty" and "social endowed beauty," but brain activity corresponding to representational and abstract stimuli (Lengger et al., 2007; Fairhall and Ishai, 2008; Cattaneo et al., 2014, 2015, 2017). 
Furthermore, Zhang et al.'s (2017) notion of a sense of beauty that responds to certain attributes is untenable given the abundant evidence showing, first, that there is no such thing as a sense of beauty and, second, that aesthetic valuation is not a response triggered by object features.

A century and a half of experimental research on art and aesthetics has yielded no trace of mental or neural processes particular to aesthetic valuation (Brown et al., 2011; Nadal, 2013; Chatterjee and Vartanian, 2014). The evidence actually shows that aesthetic valuation relies on the very same brain circuits involved in appraising the value of biologically relevant objects depending on one's state and goals (Skov, 2010; Brown et al., 2011; Salimpoor and Zatorre, 2013; Vartanian and Skov, 2014; Pearce et al., 2016; Mallik et al., 2017). These circuits compute the value of various sorts of objects and prospects, from the most basic and tangible, like food and sex, to the most abstract, like money and art (Levy and Glimcher, 2012; Ruff and Fehr, 2014; Berridge and Kringelbach, 2015). The notion of an aesthetic sense, faculty, or process is merely a vestige of Eighteenth century British Enlightenment (Kivy, 2003). It has no empirical support.

The conception of beauty as a response triggered by object features does not hold up to the evidence either. This conception is an expression of naïve realism, the composite belief that (1) properties such as color, form, or sound are attributes of objects in the world; (2) that perceiving is a stimuli-driven transformation of sensory input into coherent percepts; and (3) that the general function of cognition is to create accurate representations of the world (Neisser, 1967; Varela et al., 1991). Despite its intuitive appeal, naive realism is refuted by the most basic facts of perception and cognition. First, color, form, and sound are not properties of objects, but attributes of our experience of objects. A perceived color, for instance, does not correspond with locally reflected light. Color constancy, simultaneous color contrast, and other phenomena demonstrate that "we cannot account for our experience of color as an attribute of things in the world by appealing simply to the intensity and wavelength composition of the light reflected from

\section{REFERENCES}

Alink, A., Schwiedrzik, C. M., Kohler, A., Singer, W., and Muckli, L. (2010). Stimulus predictability reduces responses in primary visual cortex. J. Neurosci. 30, 2960-2966. doi: 10.1523/JNEUROSCI.3730-10.2010

Bar, M. (2004). Visual objects in context. Nat. Rev. Neurosci. 5, 617-629. doi: $10.1038 / \mathrm{nrn} 1476$

Berridge, K. C., and Kringelbach, M. L. (2015). Pleasure systems in the brain. Neuron 86, 646-664. doi: 10.1016/j.neuron.2015.02.018

Brieber, D., Nadal, M., and Leder, H. (2015). In the white cube: museum context enhances the valuation and memory of art. Acta Psychol. 154, 36-42. doi: 10.1016/j.actpsy.2014.11.004

Brown, S., Gao, X., Tisdelle, L., Eickhoff, and Liotti, M. (2011). Naturalizing aesthetics: brain areas for aesthetic appraisal across sensory modalities. Neuroimage 58, 250-258. doi: 10.1016/j.neuroimage.2011.06.012

Bruner, J. (1990). Acts of Meaning. Cambridge, MA: Harvard University Press.

Cattaneo, Z., Lega, C., Ferrari, C., Vecchi, T., Cela-Conde, C. J., Silvanto, J., et al. (2015). The role of the lateral occipital cortex in aesthetic appreciation of representational and abstract paintings: a TMS study. Brain Cogn. 95, 44-53. doi: 10.1016/j.bandc.2015.01.008 an area" (Varela et al., 1991, p. 160-161). Second, the brain is not a stimuli-driven system that reacts to external triggers, and perception is not a passive taking-in of stimuli (Neisser, 1967; Singer, 2013). Rather, the brain is a prediction-driven system that anticipates input, and perception is the active comparing of sensory features with predictions based on stored knowledge (Clark, 2013; Engel et al., 2013), past experience (Alink et al., 2010), global configuration (Murray et al., 2002), expectations (Egner et al., 2010), and context (Bar, 2004; Oliva and Torralba, 2007). Third, the function of cognition is not to produce an accurate representation of the world, but to bring meaning to it. We do so by interacting with the world based on what we know and believe about it, what we expect from it, and what we need and want from it (Bruner, 1990).

In sum, there is no such thing as a sense of beauty that responds to certain object attributes. If anything, beauty is an attribute of our experience of objects brought about by the activity of domain-general brain systems that seek to make meaning of those objects, their features, and their value to us, based on expectations and predictions (Salimpoor et al., 2011; Egermann et al., 2013), beliefs (Kirk et al., 2009b; Noguchi and Murota, 2013; Locher et al., 2015; Pelowski et al., 2017b), prior experience and expertise (Kirk et al., 2009a; Harvey et al., 2010; Pang et al., 2013), currently available information (Lengger et al., 2007; Swami, 2013), and context (Gartus and Leder, 2014; Brieber et al., 2015; Pelowski et al., 2017a).

\section{AUTHOR CONTRIBUTIONS}

MN and VG conceived the research. MN, VG, and GM wrote the paper together.

\section{FUNDING}

This research was supported by grant PSI2016- 77327-P, awarded by the Spanish Ministerio de Economía, Industria y Competitividad.

Cattaneo, Z., Lega, C., Gardelli, C., Merabet, L. B., Cela-Conde, C. J., and Nadal, M. (2014). The role of prefrontal and parietal cortices in aesthetic appreciation of representational and abstract art: a TMS study. Neuroimage 99, 443-450. doi: 10.1016/j.neuroimage.2014.05.037

Cattaneo, Z., Schiavi, S., Silvanto, J., and Nadal, M. (2017). A TMS study on the contribution of visual area V5 to the perception of implied motion in art and its appreciation. Cogn. Neurosci. 8, 59-68. doi: 10.1080/17588928.2015.1083968

Chatterjee, A. (2011). Neuroaesthetics: a coming of age story. J. Cogn. Neurosci., 23, 53-62. doi: 10.1162/jocn.2010.21457

Chatterjee, A., and Vartanian, O. (2014). Neuroaesthetics. Trends Cogn. Sci. 18, 370-375. doi: 10.1016/j.tics.2014.03.003

Clark, A. (2013). Whatever next? Predictive brains, situated agents, and the future of cognitive science. Behav. Brain Sci. 36, 1-24. doi: 10.1017/S0140525X12000477

Egermann, H., Pearce, M. T., Wiggins, G. A., and McAdams. (2013). Probabilistic models of expectation violation predict psychophysiological emotional responses to live concert music. Cogn. Affect. Behav. Neurosci. 13, 533-553. doi: 10.3758/s13415-013-0161-y

Egner, T., Monti, J. M., and Summerfield, C. (2010). Expectation and surprise determine neural population responses in the ventral visual 
stream. J. Neurosci. 30, 16601-16608. doi: 10.1523/JNEUROSCI.277010.2010

Engel, A. K., Maye, A., Kurthen, M., and König, P. (2013). Where's the action? The pragmatic turn in cognitive science. Trends Cogn. Sci. 17, 202-209. doi: 10.1016/j.tics.2013.03.006

Fairhall, S. L., and Ishai, A. (2008). Neural correlates of object indeterminacy in art compositions. Conscious. Cogn. 17, 923-932. doi: 10.1016/j.concog.2007.07.005

Gartus, A., and Leder, H. (2014). The white cube of the museum vs. the gray cube of the street: the role of context in aesthetic evaluations. Psychol. Aesthet. Creat. Arts 8, 311-320. doi: 10.1037/a0036847

Harvey, A. H., Kirk, U., Denfield, G. H., and Montague, P. R. (2010). Monetary favors and their influence on neural responses and revealed preference. $J$. Neurosci. 30, 9597-9602. doi: 10.1523/JNEUROSCI.1086-10.2010

Kirk, U., Skov, M., Christensen, M. S., and Nygaard, N. (2009a). Brain correlates of aesthetic expertise: a parametric fMRI study. Brain Cogn. 69, 306-315. doi: 10.1016/j.bandc.2008.08.004

Kirk, U., Skov, M., Hulme, O., Christensen, M. S., and Zeki, S. (2009b). Modulation of aesthetic value by semantic context: an fMRI study. Neuroimage 44, 1125-1132. doi: 10.1016/j.neuroimage.2008.10.009

Kivy, P. (2003). The Seventh Sense: Francis Hutcheson and Eighteenth-Century Aesthetics. Oxford: Oxford University Press.

Lengger, P. G., Fischmeister, F. P. S., Leder, H., and Bauer, H. (2007). Functional neuroanatomy of the perception of modern art: a DC-EEG study on the influence of stylistic information on aesthetic experience. Brain Res. 1158, 93-102. doi: 10.1016/j.brainres.2007.05.001

Levy, D. J., and Glimcher, P. W. (2012). The root of all value: a neural common currency for choice. Curr. Opin. Neurobiol. 22, 1027-1038. doi: 10.1016/j.conb.2012.06.001

Locher, P., Krupinski, E., and Schaefer, A. (2015). Art and authenticity: behavioral and eye-movement analyses. Psychol. Aesthet. Creat. Arts 9, 356-367. doi: $10.1037 /$ aca0000026

Mallik, A., Chandra, M. L., and Levitin, D. J. (2017). Anhedonia to music and mu-opioids: evidence from the administration of naltrexone. Sci. Rep. 7:41952. doi: $10.1038 /$ srep41952

Murray, S. O., Kersten, D., Olshausen, B. A., Schrater, P., and Woods, D. L. (2002). Shape perception reduces activity in human primary visual cortex. Proc. Natl. Acad. Sci. U.S.A. 99, 15164-15169. doi: 10.1073/pnas.192579399

Nadal, M. (2013). The experience of art: insights from neuroimaging. Prog. Brain Res. 204, 135-158. doi: 10.1016/B978-0-444-63287-6.00007-5

Nadal, M., and Pearce, M. T. (2011). The Copenhagen Neuroaesthetics conference: prospects and pitfalls for an emerging field. Brain Cogn. 76, 172-183. doi: 10.1016/j.bandc.2011.01.009

Neisser, U. (1967). Cognitive Psychology. Englewood Cliffs, NJ: Prentice Hall.

Noguchi, Y., and Murota, M. (2013). Temporal dynamics of neural activity in an integration of visual and contextual information in an esthetic preference task. Neuropsychologia 51, 1077-1084. doi: 10.1016/j.neuropsychologia.2013.03.003

Oliva, A., and Torralba, A. (2007). The role of context in object recognition. Trends Cogn. Sci. 11, 520-527. doi: 10.1016/j.tics.2007.09.009
Pang, C. Y., Nadal, M., Müller, J. S., Rosenberg, R., and Klein, C. (2013). Electrophysiological correlates of looking at paintings and its association with art expertise. Biol. Psychol. 93, 246-254. doi: 10.1016/j.biopsycho.2012.10.013

Pearce, M. T., Zaidel, D. W., Vartanian, O., Skov, M., Leder, H., Chatterjee, A., et al. (2016). Neuroaesthetics: the cognitive neuroscience of aesthetic experience. Perspect. Psychol. Sci. 11, 265-279. doi: 10.1177/1745691615621274

Pelowski, M., Forster, M., Tinio, P. P. L., Scholl, M., and Leder, H. (2017a). Beyong the lab: An examination of key factors influencing interaction with 'real' and museum-based art. Psychol. Aesthet. Creat. Arts 11, 245-264. doi: $10.1037 / \mathrm{aca} 0000141$

Pelowski, M., Gerger, G., Chetouani, Y., Markey, P. S., and Leder, H. (2017b). But is it really art? The classification of images as "Art"/"Not Art" and correlation with appraisal and viewer interpersonal differences. Front. Psychol. 8:1729. doi: 10.3389/fpsyg.2017.01729

Ruff, C. C., and Fehr, E. (2014). The neurobiology of rewards and values in social decision making. Nat. Rev. Neurosci. 15, 549-562. doi: 10.1038/nrn3776

Salimpoor, V. N., and Zatorre, R. J. (2013). Neural interactions that give rise to musical pleasure. Psychol. Aesthet. Creat. Arts 7, 62-75. doi: 10.1037/a0031819

Salimpoor, V. N., Benovoy, M., Larcher, K., Dagher, A., and Zatorre, R. J. (2011). Anatomically distinct dopamine release during anticipation and experience of peak emotion to music. Nat. Neurosci. 14, 257-262. doi: 10.1038/nn.2726

Singer, W. (2013). Cortical dynamics revisited. Trends Cogn. Sci. 17, 616-626. doi: 10.1016/j.tics.2013.09.006

Skov, M. (2010). “The pleasure of art," in Pleasures of the Brain, eds M. L. Kringelbach and K. C. Berridge (Cambridge, MA: Oxford University Press), 270-283.

Swami, V. (2013). Context matters: investigating the impact of contextual information on aesthetic appreciation of paintings by Max Ernst and Pablo Picasso. Psychol. Aesthet. Creat. Arts 7, 285-295. doi: 10.1037/a0030965

Varela, F. J., Thompson, E., and Rosch, E. (1991). The Embodied Mind. Cognitive Science and Human Experience. Cambridge, MA: The MIT Press.

Vartanian, O., and Skov, M. (2014). Neural correlates of viewing paintings: evidence from a quantitative meta-analysis of functional magnetic resonance imaging data. Brain Cogn. 87, 52-56. doi: 10.1016/j.bandc.2014.03.004

Zhang, W., He, X., Lai, S., Wan, J., Lai, S., Zhao, X., et al. (2017). Neural substrates of embodied natural beauty and social endowed beauty: an fMRI study. Sci. Rep. 7:7125. doi: 10.1038/s41598-017-07608-8

Conflict of Interest Statement: The authors declare that the research was conducted in the absence of any commercial or financial relationships that could be construed as a potential conflict of interest.

Copyright (c) 2017 Nadal, Gallardo and Marty. This is an open-access article distributed under the terms of the Creative Commons Attribution License (CC BY). The use, distribution or reproduction in other forums is permitted, provided the original author(s) or licensor are credited and that the original publication in this journal is cited, in accordance with accepted academic practice. No use, distribution or reproduction is permitted which does not comply with these terms. 